\title{
Views and Experience on Patient Engagement in Healthcare Professionals and Patients-How Are They Different?
}

\author{
Eliza L. Y. Wong1, Siufai Lui', Annie W. L. Cheung1, Carrie H. K. Yam¹, Nicole F. Huang1, \\ Wilson W. S. Tam², Engkiong Yeoh ${ }^{1}$
}

${ }^{1}$ The Jockey Club School of Public Health and Primary Care, Faculty of Medicine, The Chinese University of Hong Kong, Hong Kong, China

${ }^{2}$ Alice Lee Centre for Nursing Studies, National University of Singapore, Singapore

Email:lywong@cuhk.edu.hk

How to cite this paper: Wong, E.L.Y., Lui, S., Cheung, A.W.L., Yam, C.H.K., Huang, N.F., Tam, W.W.S. and Yeoh, E. (2017) Views and Experience on Patient Engagement in Healthcare Professionals and $\mathrm{Pa}$ tients-How Are They Different? Open Journal of Nursing, 7, 615-629.

https://doi.org/10.4236/ojn.2017.76046

Received: April 11, 2017

Accepted: May 30, 2017

Published: June 2, 2017

Copyright (๑) 2017 by authors and Scientific Research Publishing Inc. This work is licensed under the Creative Commons Attribution International License (CC BY 4.0).

http://creativecommons.org/licenses/by/4.0/

\begin{abstract}
A patient-centered approach is used to build a therapeutic alliance between patients and the healthcare professionals in care process which should be supported by a good engagement of both parties. The study aimed to explore the gap between healthcare professionals and patients on patient engagement in hospital. It was a cross-sectional survey. 2774 doctors and nurses from Department of Medicine of public hospitals completed the self-administered questionnaire and 1042 patients discharged from corresponding wards completed the telephone interviews. Participants were interviewed using structural questionnaires. The Mann-Whitney test or Pearson's chi-square test was used to analyze the agreement between health-care professionals and patients on the views and experiences of patient engagement. A difference was considered to be statistically significant when the $\mathrm{p}$-value was $<0.05$. Although both groups valued the importance of patient engagement, there was a discrepancy on understanding, views and experiences. More healthcare professionals particularly in nursing were concerned about the possible negative impact of the engagement. The majority of healthcare professionals reported that they engaged well with patients, and perceived more difficulties than patients did. The findings highlighted the mutual understanding of patient engagement, involvement and challenges encountered by both groups in Department of Medicine, which was crucial in efforts to provide meaningful patient engagement in regards to jurisdictions, health system, specialty, discipline and background of patients. It provided insight that a collaborative strategy involving both healthcare professional and patients might be an alternative approach to improving patient engagement.
\end{abstract}




\section{Keywords}

Patient Engagement, Patient Satisfaction, Patient Experience, Patient

Centered Care

\section{Introduction}

Patient engagement in healthcare has been a concern of a series of societal movements and civil rights groups since the 1960s, including the Black/African American Civil Rights Movement for autonomy [1], the Women's Health Movement, with its a primary goal of improving health care for all women [2], the Physical Disabilities Movement, which demands equal treatment and access to health care for people with disabilities [3] [4], and the AIDS Movement, which promotes equitable access to treatment, care and prevention services and has launched anti-stigma and education campaigns [5]. The common concern shared by such movements is the importance of consumerism, and the need for a transition from patients as passive recipients of health care to their more active collaboration and taking control of their own health. A considerable amount of evidence has indicated the benefits of patient engagement for health outcomes, and the importance of improving resources and staff morale to enhance the sharing of decision-making, thereby decreasing decisional conflict, increasing adherence to treatment and lifestyle modification and building more trust [6] [7] [8]. In 1984, the World Health Organization highlighted the importance of patient engagement "to reinforce the values of solidarity, equity and human rights, while recognizing the rights of individuals to freedom of choice, participation and dignity" [9]. The Institute of Medicine has further emphasized the value of patient engagement whereby individuals have the opportunity to access appropriate medical information and clinical knowledge, enabling them to be the "source of control" in making health-care decisions [6]. Recent issues of the British Medical Journal and Health Affairs dedicated to patient engagement stressed "putting patients at the centre of health care" as a principle of care [10]-[15]. Although the benefits of engaging patients for both patients and the health system have been proven and are considered to be a cornerstone of patient-centered care, the concept of patient engagement has not been defined explicitly, and is often associated with terms such as "collaboration", "involvement", "participation", "partnership", "empowerment" and "shared decision-making" [16]. Engagement is a dynamic interpersonal process set in the context of humanistic values, in which there is mutual respect and a sharing of power [17].

Several studies have drawn attention to different components of patient engagement, but much of the research has focused on a single aspect, such as shared decision-making [18], different forms of communication [19] [20], the applications for self-management [21] [22], the use of virtual reality in rehabilitation [23] and patient education [24] [25] [26]. Furthermore, current evidence indicates that health-care staffs often have a poor understanding of their patients' perspec- 
tives with respect to their involvement in decision-making [27], desire for information [28], beliefs in the effectiveness of treatment and prognosis [29], level of health literacy [30] and emotional state [31] [32]. Patient engagement formally emerged in the 2001 Institute of Medicine report "Crossing the Quality Chasm: A New Health System for the 21st Century", which called for reforms to achieve a "patient-centered" health-care system. The understanding and experiences of patient engagement have not been evaluated systematically in the past 20 years.

To address this oversight, we explored: 1) attitudes towards patient engagement; 2) the understanding of the components of patient engagement; 3) the experiences of patient engagement during care; 4) the difficulties of involvement in the suggested components of patient engagement during routine care; 5) the major challenges to incorporating patient engagement; and 6) suggested improvements to the actions of both health-care staff and patients to enhance patient engagement. These areas represent a critical gap in the current knowledge, particularly because an understanding of the challenges and difficulties of incorporating and fostering patient engagement in a broader context is important.

\section{Methods}

\subsection{Study Design}

A cross-sectional questionnaire survey of both healthcare professionals and patients from the Departments of Medicine of all 25 public hospitals under the Hong Kong Hospital Authority was conducted between May and August 2013. The contents of questionnaires for the staff and patient survey were developed based on the literature review as well as findings of focus group discussions with healthcare professionals and patients respectively. The Department of Medicine was chosen as the study setting because it contributes a major portion (30\%) of the discharges from public hospitals, which cover about $90 \%$ of secondary and tertiary health-care services in Hong Kong provided by the Hong Kong Hospital Authority.

For the survey of healthcare professionals, all department heads of the 25 public hospitals were invited to approve the distribution of questionnaires to their staff, which totaled 6886 doctors and nurses, during the study period. A paper-based, self-administered, anonymous questionnaire was used to survey healthcare professionals, and comprised seven sections with 17 items on: 1) their attitude towards patient engagement; 2) their understanding of the components of patient engagement; 3) their experience of patient engagement during their care; 4) the difficulties of involvement in the suggested components of patient engagement during routine care; 5) the major challenges of incorporating patient engagement; 6) suggested improvements to actions to enhance patient engagement; and 7) demographics and personal details. The section on the components of patient engagement was derived from the literature and was divided into three main aspects: communication and information sharing; involvement in decision-making; and self-care and safety [33] [34] [35]. To ensure confidentiality and anonymity, healthcare professionals were requested to send the com- 
pleted questionnaires with sealed envelope to the on-site collection box or mail to the research site.

For the telephone-based patient survey, the patients were interviewed using the same structured, anonymous questionnaire which was used in the healthcare professional survey. They were enrolled from a patient discharge list from the Departments of Medicine of the corresponding consenting public hospitals provided by the Hong Kong Hospital Authority between May and August 2013. The inclusion criteria for the patient population were: Hong Kong citizens with a Hong Kong Identity Card, aged 18 years or above, Cantonese-speaking, with at least one overnight stay in one of the 17 hospitals, inpatients discharged from one of 17 hospitals within 48 hours to 1 month before interview, and able to give consent to participate in the study. According to sample size calculation, a total of 1000 successful patient cases were targeted as minimum sample size with $3 \%$ margin of error at $95 \%$ confidence interval for the survey.

\subsection{Statistical Analysis}

Data management and analysis were performed using STATA version 10. Descriptive statistics were used to analyze the attitudes to and experience of patient engagement of both the health-care professionals and patients. The MannWhitney test or Pearson's chi-square test with linear-by-linear association was used to analyze the agreement between health-care staff and patients on each element of patient engagement, experience of patient engagement, difficulties and challenges, and suggested directions to enhance patient engagement during hospital care. For all of the analyses, a difference was considered as statistically significant when the $\mathrm{p}$-value was $<0.05$.

\subsection{Ethical Approval}

This study was approved by Clinical Research Ethics Committees of the Hospital Authority. All participants were informed about their rights, and given information about the purpose of the study and details of the research procedures prior to interview. Participants were allowed to withdraw from the study at any point. For patients, initial screening for eligible patients was conducted and their consents to participate in the study were obtained by hospital staff. Implied consents from staff were adopted for the healthcare professional survey when they returned the filled questionnaire to us and informed verbal consent over phone from patients was further verified prior to the interview by research team. All data were kept confidential and anonymous.

\section{Results}

A total of 17 of the 25 public hospitals agreed to participate in the study; the 4531 doctors and nurses working at the Departments of Medicine of these hospitals represented $65.8 \%$ of all doctors and nurses (6886) in the 25 public hospitals with Departments of Medicine. Of the 4531 questionnaires distributed to the doctors and nurses, 2774 were completed, giving a response rate of $61.2 \%$. 
Nurses accounted for $62.3 \%$ (2351/3776) of the nursing population and doctors accounted for $54.3 \%(410 / 755)$ of the doctoral population. Nearly half of respondents (48\%) had more than 10 years of working experience and half of the respondents worked in acute settings (51\%) (Table 1). For the patient survey, a

Table 1. Demographics of healthcare and patient respondents.

\begin{tabular}{|c|c|c|c|}
\hline \multicolumn{2}{|l|}{ Healthcare Respondents N(\%) [n= 2774] } & \multicolumn{2}{|l|}{ Patient Respondents N(\%) [n $=1042]$} \\
\hline Profession & & Gender & \\
\hline Physician & $410(14.8)$ & Male & $579(55.6)$ \\
\hline Nurse & $2351(84.8)$ & Age & \\
\hline Not willing to answer/Don't know & $13(0.5)$ & Mean \pm standard deviation & $64.9(16.7)$ \\
\hline Gender & & Living in old-age home & \\
\hline Male & $620(22.4)$ & Yes & $39(3.7)$ \\
\hline Female & $2122(76.5)$ & Education level & \\
\hline Not willing to answer/Don't know & $32(1.2)$ & No formal education or kindergarten & 198(19.0) \\
\hline Age & & Primary & $346(33.2)$ \\
\hline $18-29$ & $737(26.6)$ & Secondary (F.1-F.5) & $354(34.0)$ \\
\hline $30-39$ & $968(34.9)$ & Matriculation (F.6-F.7) & $24(2.3)$ \\
\hline $40-49$ & $686(24.7)$ & Post-secondary & $33(3.2)$ \\
\hline $50-59$ & $311(11.2)$ & Tertiary or above & $86(8.3)$ \\
\hline 60 and above & $13(0.5)$ & Not willing to answer/Don't know & $1(0.1)$ \\
\hline Not willing to answer/Don't know & $59(2.1)$ & Marital status & \\
\hline Job Title & & Single & $118(11.3)$ \\
\hline$\underline{\text { Doctor }}$ & & Married & $788(75.6)$ \\
\hline Interns & $9(2.2)$ & Divorced/Separated & $26(2.5)$ \\
\hline Resident & $129(31.5)$ & Widow & $106(10.2)$ \\
\hline Specialist & $63(15.4)$ & Not willing to answer/Don't know & $4(0.4)$ \\
\hline Senior Medical Officer/Assistant Consultant & $135(32.9)$ & Working status & \\
\hline Consultant/Chief of Service & $68(16.6)$ & Retired & $629(60.4)$ \\
\hline Not willing to answer/Don't know & $6(1.5)$ & Unemployed & $47(4.5)$ \\
\hline$\underline{\text { Nurse }}$ & & Full-time student & $11(1.1)$ \\
\hline Enrolled Nurse & $363(15.4)$ & Home-maker & $90(8.6)$ \\
\hline Registered Nurse (had $<5$ years experiences) & $595(25.3)$ & Full-time worker/Part-time worker & $261(25.0)$ \\
\hline Registered Nurse (had $\geq 5$ years experiences) & $896(38.1)$ & Not willing to answer/Don't know & $4(0.4)$ \\
\hline Advanced Practice Nurse/Nursing Officer & $329(14.0)$ & Receiving any government allowance ${ }^{a}$ & \\
\hline Ward Manager/Department Operations Manager & $113(4.8)$ & Yes & $546(52.4)$ \\
\hline Not willing to answer/Don't know & $55(2.3)$ & Self-perceived general health condition in past 4 weeks & \\
\hline Working experience in profession & & Very good & $13(1.3)$ \\
\hline Less than 1 year & $75(2.7)$ & Good & 183(17.6) \\
\hline $1-10$ years & $891(32.1)$ & Fair & $646(62.0)$ \\
\hline $11-20$ years & $894(32.2)$ & Poor & $177(17.0)$ \\
\hline $21-30$ years & $344(12.4)$ & Very Poor & $23(2.2)$ \\
\hline More than 30 years & $89(3.2)$ & Having any longstanding condition ${ }^{\mathrm{b}}$ & \\
\hline Not willing to answer/Don't know & $481(17.3)$ & Yes & $712(68.3)$ \\
\hline
\end{tabular}

a Types of the government allowance included 1) Comprehensive Social Security Assistant, 2) disability allowance and 3) old-age allowance. ${ }^{\mathrm{b}}$ Types of longstanding conditions included 1) deafness or server hearing impairment, 2) blindness or partially sighted, 3) a long-standing physical condition; 4) a learning disability; 5) a mental health condition, or 6) a long-standing illness such as heart disease, hypertension, diabetes or cancer etc. 
total of 1042 of the 2192 patients approached completed the interview, giving a response rate of $64 \%$. All of the interviews were carried out within 2 weeks of the eligible patients being discharged from the hospitals of Hong Kong Hospital Authority. The majority of the respondents were male (56\%), had a primary level of education or below (52\%), were married (76\%), were retired (60\%), received a government allowance (52\%) and had a chronic disease (68\%); their mean age was 65 years. Compared with the discharge population from medicine, it was similar except there were significantly higher proportion of male among the respondents (52\%) and significantly younger (mean age of 69 years). The demographics of the health-care and patient respondents are shown in Table 1.

\subsection{Attitudes toward Patient Engagement}

Figure 1 shows that both the healthcare professionals and patients agreed that patient engagement was important (95\% of healthcare professionals versus $98 \%$ of patients) and a benefit to healthcare ( $92 \%$ of healthcare professionals versus $98 \%$ of patients). However, a significantly lower proportion of patients (65\%) than healthcare professionals (90\%) agreed that patient engagement was necessary $(\mathrm{P}<0.001)$. A significantly higher proportion of healthcare professionals (40\%) than patients (7\%) were concerned about the possible negative impact of patient engagement on health care $(\mathrm{P}<0.001)$ and more nurses $(43 \%)$ than doctors $(19 \%)$ were concerned with this problem $(\mathrm{P}<0.001)$.

\subsection{Understanding the Elements of Patient Engagement}

Among the 12 stated elements of patient engagement in three main aspects in Figure 2, significant discrepancies were found between the patients' understanding and the healthcare professionals' perception of the operation of patient engagement: Communication and Information Sharing: "sharing information on

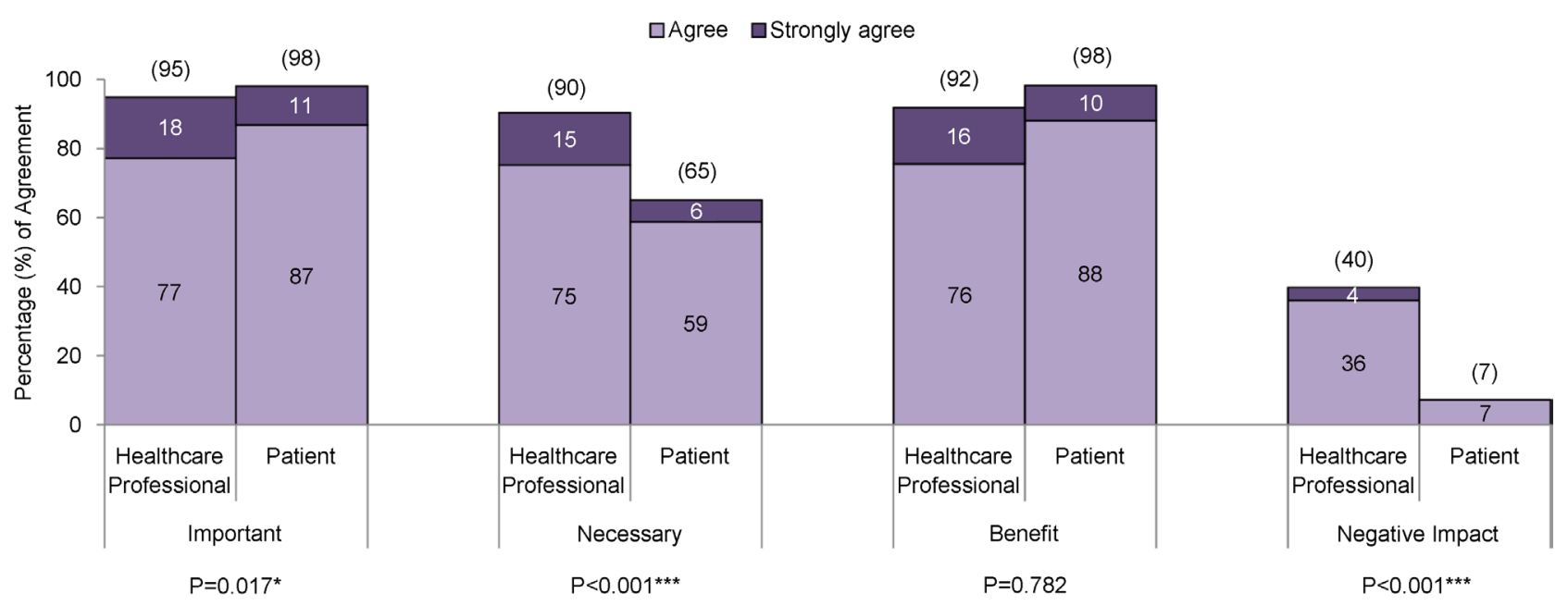

Figure 1. Agreement on importance and benefit of incorporation patient engagement into routine practice. (Mann-Whitney test was performed and a difference was considered to be statistically if $\mathrm{P}$-value was $<0.05$. ${ }^{\star} \mathrm{P}$-value $<0.05 ;{ }^{\star \star} \mathrm{P}$-value $<0.01$; ${ }_{* * *} \mathrm{P}$-value $<0.001$, which means the difference is significant at the $0.05,0.01$ and 0.001 level. Important: It is important to incorporate patient engagement. Necessary: It is necessary to incorporate patient engagement. Benefit: Incorporating patient engagement will benefit health care. Negative Impact: Incorporating patient engagement will cause negative impact on health care.) 


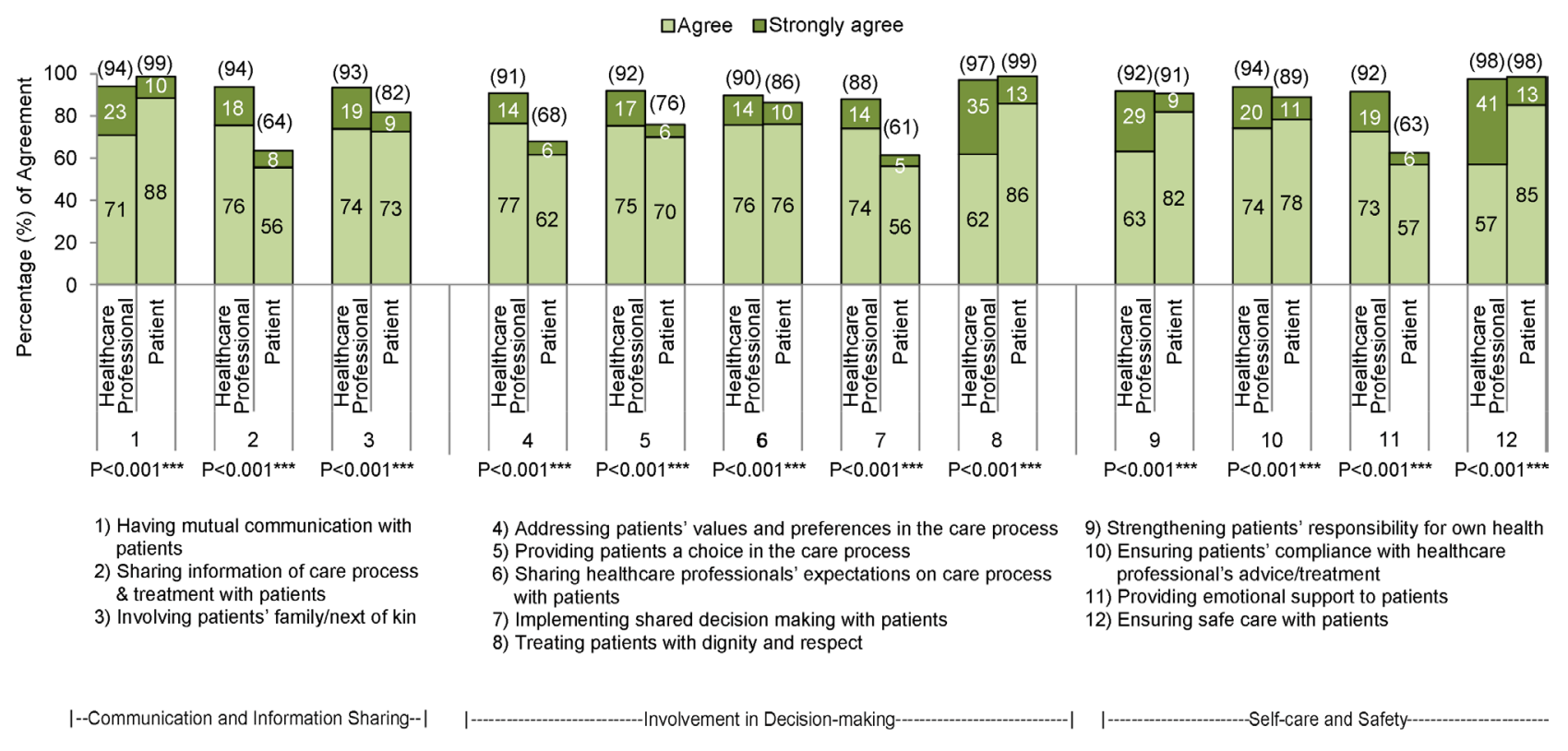

Figure 2. Agreement on 12 stated elements of patient engagement. (Chi-square tests were performed and a difference was considered to be statistically if $\mathrm{p}$-value was $<0.05 .{ }^{\star} \mathrm{P}$-value $<0.05 ;{ }^{\star \star} \mathrm{P}$-value $<0.01$; ${ }^{\star \star \star} \mathrm{P}$-value $<0.001$, which means the correlation is significant at the $0.05,0.01$ and 0.001 level.)

the care process and treatment" $(\mathrm{P}<0.001)$; Involvement in Decision-making: "addressing the patients' values and preferences in the care process" $(\mathrm{P}<0.001)$ and "implementing shared decision-making" $(\mathrm{P}<0.001)$; and Self-care and Safety: "providing emotional support" $(\mathrm{P}<0.001)$.

\subsection{Experience of Patient Engagement}

The healthcare professionals consistently perceived that they engaged patients (sometimes/always/often) in the 12 stated elements of patient engagement in Figure 3; however, the patients perceived being engaged to a significantly lower degree than that stated by the health-care staff $(\mathrm{P}<0.001)$ in Communication and Information Sharing: "sharing information on the care process and treatment with patients" ( $98 \%$ of healthcare professionals versus $68 \%$ of patients); Involvement in Decision-making: "addressing the patients' values and preferences in the care process" (95\% of healthcare professionals versus $65 \%$ of patients), "providing patients with a choice in the care process" (96\% of healthcare professionals versus $64 \%$ of patients) and "implementing shared decision-making with patients" (94\% of healthcare professionals versus $49 \%$ of patients); and Self-care and Safety: "providing emotional support to patients" (97\% of healthcare professionals versus $60 \%$ of patients). In addition, a large discrepancy was found in the degree of involvement. More than half of the healthcare professionals stated that they either "often" or "always" engaged patients in "involving patients' family/next of kin" (69\%) and "sharing health-care professionals' expectations of the care process" (52\%); however, the opposite was reported by patients, less than half of whom felt that they were "often" or "always" engaged ( $29 \%$ and $31 \%$, respectively). 


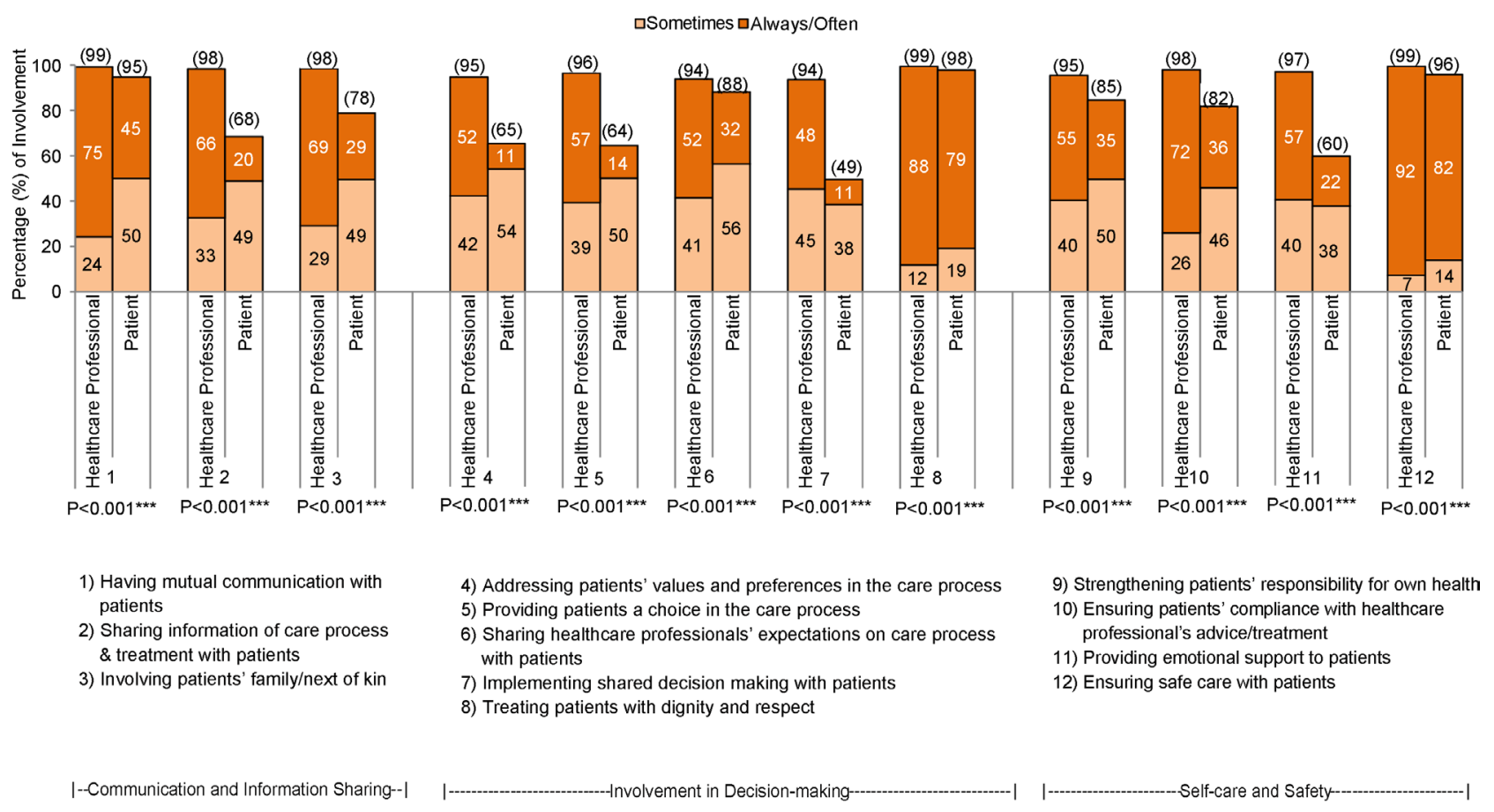

Figure 3. Perceived involvements of 12 stated elements of patient engagement. (Mann-Whitney test was performed and a difference was considered to be statistically if $\mathrm{P}$-value was $<0.05 .{ }^{\star} \mathrm{P}$-value $<0.05$; ${ }^{\star \star} \mathrm{P}$-value $<0.01$; ${ }^{\star * \star} \mathrm{P}$-value $<0.001$, which means the correlation is significant at the $0.05,0.01$ and 0.001 level.)

\subsection{Difficulties of Involvement in the Suggested Elements of Patient Engagement}

In general, significantly more healthcare professionals than patients perceived difficulties with patient engagement, as shown in Figure $4(\mathrm{P}<0.001)$. The eight components identified by the majority of healthcare staff were "involving patients' family/next of kin" (62\%), "addressing the patients' values and preferences in the care process" (59\%), "providing patients with a choice in the care process" (53\%), "sharing health-care professionals' expectations of the care process with patients" (53\%), "implementing shared decision-making with patients" (60\%), "strengthening patients' responsibility for their own health" (69\%), "ensuring patients' compliance with healthcare professional's advice/treatment" (66\%) and "providing emotional support to patients" (59\%).

\subsection{Major Challenges in Incorporating Patient Engagement}

Heavy workloads, time constraints and patients with cognitive difficulties were expressed as the major challenges by both healthcare professionals $(67 \%$ and $37 \%$, respectively) and patients (65\% and $25 \%$, respectively). The healthcare professionals further highlighted the patients' attitude (47\%), the gap between the expectations of patients and healthcare staff (26\%) and patients with poor family support (23\%) as challenges, whereas the patients expressed their poor health condition (30\%), the physical setting of the hospital environment (25\%) and not knowing when or how to discuss with/ask questions of health-care staff (23\%) as barriers to engaging in the care process. 


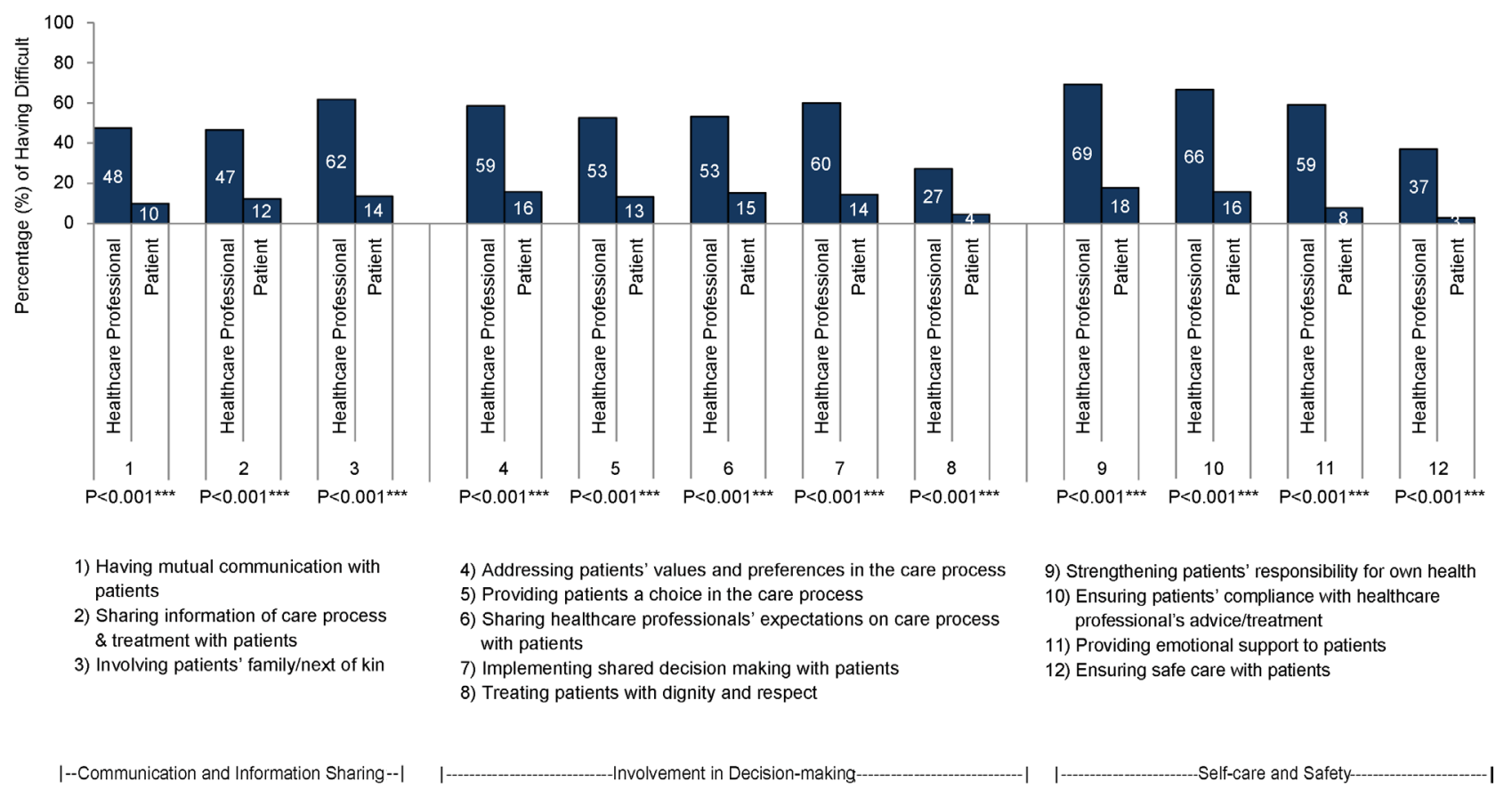

Figure 4. Perceived having difficulties of involvement in 12 stated elements of patient engagement. (Chi-square test was performed and a difference was considered to be statistically if $\mathrm{P}$-value was $<0.05$. ${ }^{\star} \mathrm{P}$-value $<0.05 ;{ }^{\star \star} \mathrm{P}$-value $<0.01$; ${ }^{\star * \star} \mathrm{P}$-value $<$ 0.001 , which means the correlation is significant at the $0.05,0.01$ and 0.001 level.)

\subsection{Suggested Improvements to Actions to Enhance Patient Engagement}

To enhance patient engagement, both healthcare professionals and patients suggested reducing the workload of healthcare staff ( $95 \%$ and $78 \%$, respectively) as an important measure and the need to improve communication skills between staff and patients (97\% and 52\%, respectively) and change the style in term of atmosphere and physical setting of hospital of management to foster patient engagement ( $93 \%$ and $49 \%$, respectively). In addition, patients highlighted improving patients' health literacy (50\%) and their communication skills with health-care staff (47\%), whereas healthcare staff emphasized improving ways to disseminate to and discuss information with patients (94\%) and encouraging patient participation in self-care (94\%).

\section{Discussion}

This is a first study to explore and compare the understanding and experience of patient engagement in both healthcare professionals and patients. It therefore provides comprehensive information on the views and experiences of patient engagement from both of them in Hong Kong. The findings show that both the healthcare professionals, particularly in nursing and patient participants were aware of the importance and benefits of patient engagement. However, the healthcare professionals were concerned about the negative impact of patient engagement, which might possibly relate to their fear of the impact of patient engagement on the workload of healthcare staff, time commitments and costs [36]. Patient engagement is important in service planning and delivery to 
achieve good health outcomes and positive illness experience, and focuses on the humanitarian aspects of care, such as being treated with dignity [13]. The concern might reflect the misalignment between the healthcare professionals' knowledge and skills and the advances of movements advocating patients' rights. Nurses play a pivotal role in all phases of patient care; surprisingly, the concern about the negative impact of patient engagement was expressed by more nurses than doctors, and may be an invisible barrier to the collaborative approach to the development of a care plan and a hindrance to patient-provider communication and emotional disclosure. The patients believed that patient engagement was important and beneficial but not completely necessary. This counterintuitive finding implies that the patients' self-abasement or inability to express themselves given the unbalanced power relations with health-care staff and low health literacy. Patient engagement is conceptualized as patients' self-awareness and ability to express their physical and emotional needs, thus resulting in better orientated professional interventions [37]. Discussing preferences and views or disagreeing with a recommendation are communication skills used in everyday life, but for many patients these may be novel in the context of a medical consultation [38] [39], which could impede the development of effective self-coping strategies for disease management [37].

In terms of the understanding and logistics of patient engagement, the healthcare professionals agreed that all of the 12 stated components were important in patient engagement. In contrast, the patients emphasized the importance of the areas of Communication and Information Sharing and Self-care and Safety and put less focus on Involvement in Decision-making, which reflects with their fear of being categorized as a "difficult or unwelcome patient" by participating to a greater extent in their own health care, as expressed in the focus group and echoed by the study of Dominick et al. [40].

A large discrepancy was found in the experiences of patient engagement among the healthcare professionals and patients. The majority of the healthcare professionals believed that they had engaged patients across the 12 components of patient engagement; however, the majority of patients did not feel that they were being engaged in the care process. Besides "ensuring safe care with patients" and "treating and receiving patients with dignity and respect", which were well aligned between health-care staff and patients, the health-care staff had a poor understanding of patient engagement from the patients' perspective, in particular with regard to the aspects of communication and information sharing and involvement in decision-making, a finding also reflected in previous studies [27]-[32] [41] [42] [43]. Similar to two previous reviews, we found that the provider's knowledge of and attitude towards patient engagement were a barrier to implementation [44] [45].

In addition to the heavy workloads/time constraints and communication skills of healthcare professionals, our study uncovered another barrier to patient engagement: a lack of certain physical and cognitive abilities and communication skills among patients and the physical setting of the hospital. This finding pro- 
vides valuable input for strategies to help patients to engage in the caring process, which previously have only focused on healthcare staff, such as their training in communication skills and the development of decision tools. Implementation models are unlikely to succeed if patient engagement relies solely on healthcare staff to initiate communication with patients and distribute decision aids. Strategies that encourage patients and improve facilities, such as improving health literacy and the physical environment, are promising alternatives.

A successful implementation may also depend on the development of clinical information systems that can track each patient's progress throughout the entire process of patient engagement and identify the most difficult steps in this process. Our findings also have implications for suggesting measures to improve patient engagement, which might include a system to disseminate information to patients effectively, a training workshop in communication skills for healthcare staff and patients, and health literacy education for patients. Management fostering of patient engagement, in terms of both staff and the physical setting of the hospital, and creating an atmosphere to encourage patients to participate in self-care could help to ensure meaningful engagement. Incentives that target areas other than the volume of visits and greater care coordination may be necessary for patient engagement to take hold.

The study has some limitations. As the recruitment of the study was from the department of medicine in the selected public acute and rehabilitation hospitals only, the voices and experiences of patient engagement in other departments in the hospitals are not clear.

The participants who were recruited for the patient survey were significantly younger and less likely to live in an old age home than the general discharge population. The findings of the study may not be generalized to some of the patients. In addition, our study used a cross-sectional design; longitudinal studies are needed to establish its sensitivity to change.

\section{Conclusion and Policy Implications}

Patient engagement is a cornerstone of patient-centered care and is beneficial to patient health outcomes, staff morale and health system performance. An understanding of patient engagement and the involvement of and challenges encountered by both healthcare professionals and patients are crucial in efforts to provide meaningful patient engagement in different contexts in term of jurisdictions, health system, specialty, discipline, background of patients and time period. Most of the commentary assumes patients are homogenous and healthcare staff is likewise homogenous. Our findings show the differences between healthcare professionals and patients in their understanding, views and experiences of patient engagement in Hong Kong public health sector and it could be used as a lesson to be shared and reference to be compared. According to the framework of the Continuum of Patient and Representative Group Engagement of NHS Trusts developed from "A Ladder of Citizen Participation" [46], there are three phases of citizen engagement across six ladders: the Passive Phase (approach, 
inform); the Active Phase (consult, involve); and the Committed Phase (partner, devolve). Patient engagement in Hong Kong is in the "Active" phase of two-way communication [47]. The first step towards the Committed Phase of partnering with patients is to establish a mutual understanding and to align expectations. Development of a collaborative strategy involving the different stakeholders, including health-care staff, managers, policy makers and patients, should then be developed to transform participation in health care. Further study is required to explore understanding and experience in different health systems, disciplines and groups of patients.

\section{Acknowledgements}

This study was funded by the Hospital Authority (HA). We would like to express our heartfelt thanks to HA for giving us this valuable opportunity to do the surveys in Hong Kong public hospitals. We also wish to thank the colleagues of the Department of Patient Relations and Engagement for their assistance in conducting the study. We would like to thank Prof Sian Griffiths for her advice on the manuscript. Last but not least, we also wish to thank all staff in the selected HA hospitals for supporting, coordinating and participating the survey in their hospital and all patients who participated in the survey by providing their valuable opinions and feedback.

\section{Conflict of Interest}

The authors of this manuscript have no conflict of interest to report.

\section{References}

[1] National Empowerment Center. (2013) Articles and Information by NEC Staff and Affiliates. http://power2u.org/downloads/HistoryOfTheConsumerMovement.pdf

[2] Nichols, F.H. (2009) History of the Women's Health Movement in the 20th Century. Journal of Obstetric, Gynecologic, and Neonatal Nursing, 29, 56-64.

[3] Switzer, J.V. (2003) Disabled Rights: American Policy and the Fight for Equality. Georgetown University Press, Washington DC.

[4] Fleischer, D.Z. and Zames, F. (2001) The Disability Rights Movement: From Charity to Confrontation. Temple University Press, Philadelphia.

[5] Nunn, A., Dickman, S., Nattrass, N., Cornwall, A. and Gruskin, S. (2012) The Impacts of AIDS Movements on the Policy Responses to HIV/AIDS in Brazil and South Africa: A Comparative Analysis. Global Public Health, 7, 1031-1044. https://doi.org/10.1080/17441692.2012.736681

[6] Tang, P.C. and Lansky, D. (2005) The Missing Link: Bridging the Patient-Provider Health Information Gap. Health Affairs, 24, 1290-1295.

https://doi.org/10.1377/hlthaff.24.5.1290

[7] Verlinde, E., De Laender, N., De Maesschalck, S., Deveugele, M. and Willems, S. (2012) The Social Gradient in Doctor-Patient Communication. International Journal for Equity in Health, 11, 12. https://doi.org/10.1186/1475-9276-11-12

[8] Nelson, D.E., Kreps, G.L., Hesse, B.W., Croyle, R., Willis, G., Arora, N., et al. (2004) The Health Information National Trends Survey (HINTS): Development, Design, and Dissemination. Journal of Health Communication, 9, 443-460. 
https://doi.org/10.1080/10810730490504233

[9] Europe WHORCf. (1994) The Copenhagen Declaration on Health Policy.

[10] Hibbard, J.H. and Greene, J. (2013) What the Evidence Shows about Patient Activation: Better Health Outcomes and Care Experiences; Fewer Data on Costs. Health affairs, 32, 207-214. https://doi.org/10.1377/hlthaff.2012.1061

[11] Yegian, J.M., Dardess, P., Shannon, M. and Carman, K.L. (2013) Engaged Patients Will Need Comparative Physician-Level Quality Data and Information about Their Out-of-Pocket Costs. Health Affairs, 32, 328-337. https://doi.org/10.1377/hlthaff.2012.1077

[12] Moynihan, R. (2013) The Future of Medicine Lies in Truly Shared Decision Making. $B M J, 346$, f2789. https://doi.org/10.1136/bmj.f2789

[13] Black, N. (2013) Patient Reported Outcome Measures Could Help Transform Healthcare. BMJ, 346, f167. https://doi.org/10.1136/bmj.f167

[14] Stiggelbout, A.M., Van der Weijden, T., De Wit, M.P., Frosch, D., Légaré, F., Montori, V.M., et al. (2012) Shared Decision Making: Really Putting Patients at the Centre of Healthcare. BMJ, 344, e256. https://doi.org/10.1136/bmj.e256

[15] Hamilton, D.W. (2014) Shared Decision Making Asks Patients to Share Their Aims and Values for Treatment. BMJ, 348, g1435. https://doi.org/10.1136/bmj.g1435

[16] Cahill, J. (1998) Patient Participation-A Review of the Literature. Journal of Clinical Nursing, 7, 119-128.

[17] Ashworth, P.D., Longmate, M.A. and Morrison, P. (1992) Patient Participation: Its Meaning and Significance in the Context of Caring. Journal of Advanced Nursing, 17, 1430-1439. https://doi.org/10.1111/j.1365-2648.1992.tb02814.x

[18] Dwamena, F., Holmes-Rovner, M., Gaulden, C.M., Jorgenson, S., Sadigh, G., Sikorskii, A., et al. (2012) Interventions for Providers to Promote a Patient-Centred Approach in Clinical Consultations. The Cochrane Database of Systematic Reviews, No. 12, CD003267. https://doi.org/10.1002/14651858.cd003267.pub2

[19] De Jongh, T., Gurol-Urganci, I., Vodopivec-Jamsek, V., Car, J. and Atun, R. (2012) Mobile Phone Messaging for Facilitating Self-Management of Long-Term Illnesses. The Cochrane Database of Systematic Reviews, No. 12, CD007459. https://doi.org/10.1002/14651858.cd007459.pub2

[20] Cash-Gibson, L., Felix, L.M., Minorikawa, N., Pappas, Y., Gunn, L.H., Majeed, A., et al. (2012) Automated Telephone Communication Systems for Preventive Healthcare and Management of Long-Term Conditions (Protocol). The Cochrane Database of Systematic Reviews, No. 7, CD009921.

[21] Pal, K. (2013) Computer-Based Diabetes Self-Management Interventions for Adults with Type 2 Diabetes Mellitus. Journal of Evidence-Based Medicine, 6, 119-120. https://doi.org/10.1111/jebm.12042

[22] Murray, E., Burns, J., See, T.S., Lai, R. and Nazareth, I. (2005) Interactive Health Communication Applications for People with Chronic Disease. The Cochrane Database of Systematic Reviews, No. 4, CD004274.

[23] Laver, K.E., George, S., Thomas, S., Deutsch, J.E. and Crotty, M. (2011) Virtual Reality for Stroke Rehabilitation. The Cochrane Database of Systematic Reviews, No. 9, CD008349. https://doi.org/10.1002/14651858.cd008349.pub2

[24] Ciciriello, S., et al. (2013) Multimedia Educational Interventions for Consumers about Prescribed and Over-the-Counter Medications. The Cochrane Database of Systematic Reviews, No. 4, CD008416.

[25] Freemantle, N., Harvey, E.L., Wolf, F., Grimshaw, J.M., Grilli, R. and Bero, L.A. (2000) Printed Educational Materials: Effects on Professional Practice and Health 
Care Outcomes. The Cochrane Database of Systematic Reviews, No. 2, CD000172.

[26] Forster, A., Brown, L., Smith, J., House, A., Knapp, P., Wright, J., et al. (2012) Information Provision for Stroke Patients and Their Caregivers. The Cochrane Database of Systematic Reviews, No. 11, CD001919. https://doi.org/10.1002/14651858.cd001919.pub3

[27] Strull, W.M., Lo, B. and Charles, G. (1984) Do Patients Want to Participate in Medical Decision Making? JAMA, 252, 2990-2994. https://doi.org/10.1001/jama.1984.03350210038026

[28] Willems, S., De Maesschalck, S., Deveugele, M., Derese, A. and De Maeseneer, J. (2005) Socio-Economic Status of the Patient and Doctor-Patient Communication: Does It Make a Difference? Patient Education and Counseling, 56, 139-146. https://doi.org/10.1016/j.pec.2004.02.011

[29] Quirt, C.F., Mackillop, W.J., Ginsburg, A.D., Sheldon, L., Brundage, M., Dixon, P., et al. (1997) Do Doctors Know When Their Patients Don't? A Survey of Doctor-Patient Communication in Lung Cancer. Lung Cancer, 18, 1-20. https://doi.org/10.1016/S0169-5002(97)00048-2

[30] Kelly, P.A. and Haidet, P. (2007) Physician Overestimation of Patient Literacy: A Potential Source of Health Care Disparities. Patient Education and Counseling, 66, 119-122. https://doi.org/10.1016/j.pec.2006.10.007

[31] Hall, J.A., Stein, T.S., Roter, D.L. and Rieser, N. (1999) Inaccuracies in Physicians' Perceptions of Their Patients. Medical Care, 37, 1164-1168.

https://doi.org/10.1097/00005650-199911000-00008

[32] Butow, P.N., Brown, R.F., Cogar, S., Tattersall, M.H. and Dunn, S.M. (2002) Oncologists' Reactions to Cancer Patients' Verbal Cues. Psycho-Oncology, 11, 47-58. https://doi.org/10.1002/pon.556

[33] Cartwright, J. and Crowe, S. (2001) Patient and Public Involvement Toolkit. Wiley-Blackwell and BMJI Books, London.

[34] Kitson, A., Marshall, A., Bassett, K. and Zeitz, K. (2013) What Are the Core Elements of Patient-Centred Care? A Narrative Review and Synthesis of the Literature from Health Policy, Medicine and Nursing. Journal of Advanced Nursing, 69, 4-15. https://doi.org/10.1111/j.1365-2648.2012.06064.x

[35] Wong, E.L., Leung, M.C., Cheung, A.W., Yam, C.H., Yeoh, E.K. and Griffiths, S. (2011) A Population-Based Survey Using PPE-15: Relationship of Care Aspects to Patient Satisfaction in Hong Kong. Journal of the International Society for Quality in Health Care, 23, 390-396.

[36] McCarthy, M. (2013) Patient Participation in Decision Making May Raise Cost of Care, Study Shows. BMJ, 346, f3597. https://doi.org/10.1136/bmj.f3597

[37] Prey, J.E., Woollen, J., Wilcox, L., Sackeim, A.D., Hripcsak, G., Bakken, S., et al. (2014) Patient Engagement in the Inpatient Setting: A Systematic Review. Journal of the American Medical Informatics Association, 21, 742-750. https://doi.org/10.1136/amiajnl-2013-002141

[38] Frosch, D.L., Legare, F., Fishbein, M. and Elwyn, G. (2009) Adjuncts or Adversaries to Shared Decision-Making? Applying the Integrative Model of Behavior to the Role and Design of Decision Support Interventions in Healthcare Interactions. Implementation Science, 4, 73. https://doi.org/10.1186/1748-5908-4-73

[39] Entwistle, V.A., McCaughan, D., Watt, I.S., Birks, Y., Hall, J., Peat, M., et al. (2010) Speaking Up about Safety Concerns: Multi-Setting Qualitative Study of Patients' Views and Experiences. Quality and Safety in Health Care, 19, 1-7.

[40] Frosch, D.L., May, S.G., Rendle, K.A., Tietbohl, C. and Elwyn, G. (2012) Authorita- 
rian Physicians and Patients' Fear of Being Labeled "Difficult" among Key Obstacles to Shared Decision Making. Health Affairs, 31, 1030-1038.

https://doi.org/10.1377/hlthaff.2011.0576

[41] Suarez-Almazor, M.E., Conner-Spady, B., Kendall, C.J., Russell, A.S. and Skeith, K. (2001) Lack of Congruence in the Ratings of Patients' Health Status by Patients and Their Physicians. Medical Decision Making, 21, 113-121.

[42] Teno, J.M., Hakim, R.B., Knaus, W.A., Wenger, N.S., Phillips, R.S., Wu, A.W., et al., The SUPPORT Investigators (1995) Preferences for Cardiopulmonary Resuscitation: Physician-Patient Agreement and Hospital Resource Use. Journal of General Internal Medicine, 10, 179-186. https://doi.org/10.1007/BF02600252

[43] Hall, J.A., Horgan, T.G., Stein, T.S. and Roter, D.L. (2002) Liking in the PhysicianPatient Relationship. Patient Education and Counseling, 48, 69-77. https://doi.org/10.1016/S0738-3991(02)00071-X

[44] Legare, F., Stacey, D., Turcotte, S., Cossi, M.J., Kryworuchko, J., Graham, I.D., et al. (2014) Interventions for Improving the Adoption of Shared Decision Making by Healthcare Professionals. The Cochrane Database of Systematic Reviews, No. 9, CD006732.

[45] Legare, F., Ratte, S., Gravel, K. and Graham, I.D. (2008) Barriers and Facilitators to Implementing Shared Decision-Making in Clinical Practice: Update of a Systematic Review of Health Professionals' Perceptions. Patient Education and Counseling, 73, 526-535. https://doi.org/10.1016/j.pec.2008.07.018

[46] Arnstein, S.R. (1969) A Ladder of Citizen Participation. Journal of the American Planning Association, 35, 216-224. https://doi.org/10.1080/01944366908977225

[47] Cambridgeshire Community Service-NHS (2014) Patient and Public Engagement Strategy. National Health Service, Editor, UK, 2014.

\section{Scientific Research Publishing}

Submit or recommend next manuscript to SCIRP and we will provide best service for you:

Accepting pre-submission inquiries through Email, Facebook, LinkedIn, Twitter, etc. A wide selection of journals (inclusive of 9 subjects, more than 200 journals)

Providing 24-hour high-quality service

User-friendly online submission system

Fair and swift peer-review system

Efficient typesetting and proofreading procedure

Display of the result of downloads and visits, as well as the number of cited articles

Maximum dissemination of your research work

Submit your manuscript at: http://papersubmission.scirp.org/

Or contact ojn@scirp.org 